\title{
Wandering in Care Homes: The Role of Artists in Reimagining Walking Performed by People Living with Dementia
}

Jayne Lloyd

University of Brighton, Brighton, UK

J.Lloyd4@brighton.ac.uk

Key words: walking, wandering, dementia, arts, performance

Word count: 8392

\begin{abstract}
Walking by those living with dementia is often pathologically labelled 'wandering' (Marshall 2006), an act lacking a clear purpose or destination. Walking in this context is not widely understood or valued, except as physical exercise. Drawing on walking performances by other artists and the author's own arts-based research, during which she walked outdoors and in care homes with people living with dementia, this article explores the role that the performance and conceptualisation of walking by artists can play in challenging and reimagining walking undertaken by people living with dementia.
\end{abstract}

This article explores the role that the performance and conceptualisation of walking by artists can play in challenging and reimagining walking undertaken by people living with dementia. Through a discussion of walking performances by other artists and my own artsbased research during which I walked in care homes with people living with dementia and outdoors, I examine the possibilities and challenges of arts projects that engage with walking in care homes. I focus on two questions that arose in my research about how artists and care home residents living with dementia can walk together and what role, if any, the act of walking can play in the life of a care home resident who cannot physically walk far and does not often go outside. Firstly, I identify differences between the relationships people living with dementia and artists who walk as part of their arts practice can have to walking. I question the creative possibilities and ethical issues these differences raise. Secondly, I question how artists can evoke in a care home a feeling of going for a walk and a sense of the outdoor environments in which walking can take place. Considering this question, I explore how co-facilitating an arts session with a dancer who has a more durational, rhythmic and performative practice than my visual art practice enabled us to create an experience of going for a walk outside without physically leaving the care home living room. 
I propose that inter-disciplinary collaborations between artists can cross-fertilise and extend the possibilities of arts disciplines and their potential to creatively engage people living with dementia in the embodiment and materiality of everyday experiences. To understand how my approach to facilitating a session was enhanced during the collaboration I apply theatre practitioner and researcher Sue Mayo's concept of arts practices being predisposed to different 'shapes', which is her observation that in participatory arts projects arts practices fall into natural configurations that create different 'shapes in the room' (Mayo 2012: 30). Visual arts activities she observes enable connections between 'art partners' (Mayo 2012: 30) who are working closely together on an activity, but not an awareness of the group as a whole. She found that introducing performative activities into participatory arts sessions opened out the shape of the arts practice and participants became aware of more of the other people in the group. In this article I extend the concept of arts practices or activities having different shapes through an exploration of how the performance of walking actions can create an awareness of other members of the group, the care home environment and an evocation of environments in which those participating in the actions have previously taken walks.

The essay is an extract of my practice-based $\mathrm{PhD}$ research that critically engaged with Reminiscence Arts and Dementia Care: Impact on Quality of Life (RADIQL) ${ }^{1}$. The wider RADIQL research project aimed to evidence the impact of Age Exchange's Reminiscence Arts practice on participants' health and wellbeing. My research responds to a need to understand the arts practices and processes involved in interventions that aim to have an impact on health and wellbeing rather than only measuring health impacts of participating in arts projects. My role as an artist in the research team ${ }^{2}$ was to deepen an understanding of the practice and make the tacit knowledge of Age Exchange's Reminiscence Arts

\footnotetext{
${ }^{1}$ My PhD research critically engaged with Reminiscence Arts and Dementia Care: Impact on Quality of Life (RADIQL). RADIQL was a three-year programme of creative activities for care home residents living with dementia which ran from 2012 to 2015. It was designed and led by Age Exchange Theatre Trust and funded by Guy's and St. Thomas' Charity.

${ }^{2}$ The research was conducted by a team of researchers from Royal Holloway, University of London. The other members of the research team were: Professor Helen Nicholson, Professor of Applied Performance; Dr Frank Keating, Senior Lecturer in Social Work; Dr Laura Cole, a social psychologist.
} 
Practitioners (RAPs) explicit so it could be shared to evidence, sustain and further develop the quality and impact of Age Exchange's practice and contribute to the burgeoning field of arts and dementia. Studies of the health and wellbeing outcomes of arts projects for people living with dementia predominantly attempt to measure the effects of art as part of a treatment that supplements or replaces pharmacological interventions (Zeilig et al. 2014, De Medeiros \& Basting 2014). In turn, art is measured against the same criteria as medical treatments and the research is conducted by researchers from the sciences. The emergence of projects that include artists as part of the research team indicates a growing acknowledgement that artists have a contribution to make to this area of study. Notable projects include, Dementia and Imagination: Creating Community Connections Through Art (2013-17), the Doctoral Training Centre for The Arts and Dementia (TAnDem) and the Wellcome Trust's Hub Residency, Created Out of Mind. In the wider field of arts and health, the 2017 Creative Health: The Arts for Health and Wellbeing report valued the knowledge and experience of arts professionals by taking evidence from a number of arts organisations. There is still more to be done, however, to understand and communicate the specificities and nuances of different arts practices and the role of artists working with people living with dementia.

My research involved observing workshops facilitated by Age Exchange's RAPs and delivering my own sessions developed in response. In this article I discuss two of the sessions I delivered as part of this research. Walking became a focus of my PhD research because Reminiscence Arts combines reminiscence practices with arts practices and the focus of the reminiscences is often everyday activities participants used to do before entering residential care. One of these everyday activities that kept reoccurring as a theme in the sessions I observed and in conversations with care home residents was walking. In one care home a resident told me about walks she used to take with her dog. One of the projects I discuss is a series of one-to-one sessions I developed in response. The other project I discuss took place in another care home where walking formed part of a series of group sessions that explored the wider theme of evoking outdoor experiences in a care home lounge and was co-facilitated with Christina Argyropoulou, a dance movement psychotherapist and community dance practitioner and one of Age Exchange's RAPs. Walking also became a focus for this research because of the lack of opportunities care 
home residents living with dementia have to walk. Despite being an everyday activity, walking is not equally accessible to everybody. Social, political and environmental barriers to walking are faced by women (Heddon \& Turner 2012), refugee and asylum seekers (Myers 2017) and people living with disabilities (Porter \& Heddon 2014 ). Care home residents living with dementia face specific barriers to walking. These are created because of impairments associated with their dementia and other disabilities that come with age. The environment in which they live and a lack of understanding of why they walk and how best their walking can be supported further limits their opportunities to go for a walk. These barriers and how the arts can support them to be overcome are discussed in the proceeding sections of this article.

\section{The Care Home Environment: Walking with Bruce Nauman}

Artists who walk as part of their practice usually walk outdoors. A notable exception is Bruce Nauman's early video art piece Walking in an Exaggerated Manner Around the Perimeter of a Square (1967-68) which took place indoors. Watching Nauman as he walks in a purposefully exaggerated manner repetitively round the edge of a square marked out with masking tape on the floor of a studio, emphasised to me the absurdity of going for a walk indoors. Despite his slightly comedic performance, the banality of the act makes for tedious viewing. Within the constraints he has set himself the scenery stays the same throughout the video and the walker does not reach a destination.

Going for a walk indoors was not something that I had contemplated before I began frequenting care homes. Whilst I do walk in my house, I would not describe it as going for a walk. Walks at home are generally task orientated; I would say, for example, that I was going to put the kettle on, going to bed or going to the living room. They also cover a significantly shorter distance than I would describe as 'a walk'. Between 2012-2014 I regularly visited 6 care homes as part of my research. The care homes were not identical to each other. What they all had in common, however, was that residents were locked in. The series of security doors I had to go through to access the care home made me very aware that there was a clear physical separation between the world inside the care home and anything outside its boundaries. As a visitor I moved between these two worlds, but the 
care home residents rarely did. Further, there were limited opportunities for residents to go for a walk and the walking that I did observe taking place often did so indoors.

In response to the restricted access care home residents had to the outdoors, I began a project with $\mathrm{Mary}^{3}$, a resident, who told me about walking her dog on the local Common. Mary used to be a keen walker and her eagerness to talk about her dog walks demonstrated that they had been an important daily pursuit, but she had lost this as an activity in her life. Between the 22nd May and the 31st July 2014 I visited her in her care home every week for 10 weeks to learn more about these walks and the role walking played in her life now she was in residential care. The only walks Mary and I went on together took place indoors in the care home corridor that linked the lounge, where she was usually sitting when I arrived, to the dining room, where we explored the walks she used to take on the Common. When I arrived at the care home each week Mary was sitting in the same seat, as were most of the care home residents I encountered during my research. One or two residents in each home were exceptions, and throughout my weekly visits they would walk up and down the corridors. When Mary and I made our way to and from the dining room each week we invariably passed a resident who repetitively walked the length of the corridor. This corridor was the only space in the care home in which to walk any distance and the resident who repetitively walked it was making do with what was available to her.

I realised that any understanding of how an experience of walking outdoors related to Mary's life in the care home necessitated that I learnt how both the care home and the outdoors can be experienced as environments in which to walk. As part of this project, therefore, I walked both on the Common and with Mary in the care home and walking became an important part of my research. Approaching our traversal of the corridor as a walk raised my awareness of it as a place to walk. Typical of the corridors in all the care homes I visited, the one I walked down with Mary was fitted with broad handrails on both walls that stretched the full length of it. We walked on laminate flooring that was smooth with a matt surface, clear of trip hazards and on the flat. These attributes of the corridor

\footnotetext{
${ }^{3}$ The participant's name has been changed to conceal her identity in accordance with the ethical approval the research received.
} 
seemed to be designed to support residents to walk in the care home. My assumption was affirmed when I found that the corridor exemplified many of the recommendations for creating a safe environment in which older adults living with dementia could walk, as set out in Health Building Notes 08-02: Dementia-friendly Health and Social Care Environments (2015), a guidance document that advises health and social care providers on the development, maintenance and refurbishment of dementia-friendly health and social care environments. Recognising the environment as an important factor in the quality of care and the lives of people with dementia, it sets out twelve principles for designing health and social care environments, including care homes. The first, which is described as overarching, is to provide a safe environment. The rationale behind this is as follows:

People living with dementia require health and social care environments that are safe, secure and easy to move around, so that they are to make the best of their remaining abilities. (Department of Health 2015: 25)

This leads to the following recommendations of what the care environments should provide to support walking:

[A]ppropriate design features (e.g. increased intensity of lighting and contrast, handrails that contrast with their background, appropriate walking aids, slipresistant, matt finished flooring with no patterns and shadows, contrasting texture and/or colours at the beginning and ends of the stairs, contrasting leading edges on stairs, and appropriate technology and sensors) to reduce the risk of slips, trips and falls. (Department of Health 2015: 25)

Whilst care homes often have design features that support their residents to walk, the focus on safety and the fact that the care home corridors are indoor spaces leads to them being a much less materially and sensorially diverse place to do so than any outdoor environment. When care home residents walk in corridors the textures and sensations of the outdoors are not available to them. They cannot crunch fallen leaves under their feet, smell freshly cut grass, get soaked by the rain or feel the hot sun or cool wind on their faces. Mary undertook 
our walks in her slippers. Their lack of waterproofing and flimsy soles further served to emphasise that these were indoor shoes worn by someone who was walking indoors.

As Mary and I trod the same path each week the scenery was unchanging and it brought to mind Nauman's video. The ludicrousness of thinking of this as going for a walk did not escape me. It is indoors in corridors, however, that most care home residents walk. Many care homes are designed with circular walking routes that extend the distance a resident can walk in one direction, but this also mirrors the repetitiveness and mundanity of Nauman's circuit around the room. Corridors forming circular walking routes, tracking devices, supervision and locked doors may increase safety, but they also significantly reduce freedom and can keep people physically and metaphorically 'locked in'. Artists, including Nauman, often engage with mundanity and find interest in repetition and process as well as in walking itself, pointing to the possibility that artists could conceptualise, communicate and reimagine how these spaces are and could be experienced as places to walk. This is explored further in the remainder of this research essay.

\section{Walking with Dementia: Mis-guides and Dérives}

Walking is a normal part of the vast majority of people's lives. Mary Marshall, an academic from the field of social work, argues, however, that whilst walking by people living with dementia is a continuation of something people do throughout their lives, it is often not understood as such. She proposes that walking is regularly seen as a problematic symptom of the person's dementia leading it to be negatively dismissed as 'wandering'. Conveying her sentiments about how walking by people living with dementia is seen, Marshall introduces Dementia: Walking not Wandering: Fresh Approaches to Understanding and Practice (2006) by writing:

This book grew out of an awareness of the paradox that walking is normal and healthy but when people with dementia do it, it is pathologically labelled 'wandering'. (Marshall 2006: 10)

Marshall argues that wandering is a prevalent but unhelpful term when used to describe walking undertaken by people living with dementia. Significantly, she argues that when 
people with dementia walk it is not aimless, as the definition of the word 'wandering' implies, but using this word to describe it enables it to be dismissed as such. The term is, therefore, derogatory and alleviates the need to question why the walking was undertaken. Compellingly, it is a concern that residents might 'wander off' that leads to them being locked in the care home. Marshall recognises there are reasons for restricting the freedom of people living with dementia, but questions whether stopping someone walking is always the most appropriate way to look after them. She writes:

Clearly, there are issues of safety and quality of life in some walking by people with dementia, but we have to ask ourselves whether the response of those in dementia care is always one that treats those with dementia as fellow citizens. (Marshall 2006: 10)

Concern for residents' safety often prevents them from being allowed to go outside unaccompanied, but their walking may also appear strange or aimless when undertaken in the care home because there is a mismatch between it and their current situation. Faith Gibson, another social work academic writing in the same publication as Marshall, discusses how the act of walking may no longer be appropriate or germane to the environment or time in which it is performed. As she writes, "[o]ccupational remnant' is a phrase used to describe behaviour appropriate to an earlier stage that intrudes into the present where it is no longer relevant' (Gibson 2006: 64). Performing occupational or recreational remnants can be disturbing and frustrating for people with dementia who do not always have an awareness that what they are doing is no longer part of their lives in the way it once was. Their walking can be seen as problematic by their carers who may not understand why they are doing something that seems bizarre, out of place and potentially disruptive.

Mary, the care home resident who used to walk her dog on the Common, was not a 'wanderer' in the sense that she did not continually walk. The enthusiasm and readiness with which she talked about walking, however, demonstrated the same intensity of connection to walking that was exhibited by those care home residents I encountered who did continue to walk long distances in the care home. Further, her recreational remnant of dog walking often became intertwined with her current life. Instead of missing the walks she 
used to take on the Common I found Mary often merged recollections of them with her experiences of old age and living in a care home. Notably, in response to photographs and films I took of my walks on the Common, artefacts I brought in and questions I asked her, Mary often discussed her dog and the walks she used to take him on in the present tense, regularly describing him as if he was still alive and as if she still walked him on the Common. Further, I noted that in our sessions she often referenced her dog walks when she described to me what she was currently experiencing. When I greeted her at the beginning of the sixth session, for example, one of the first things she shared with me was that her legs were tired, and this was followed by her explanation that 'it must be all the dog walking'. This was said in a friendly but sincere tone that led me to interpret her comment to mean that she really believed, on some level at least, that she had recently been on a dog walk. In this instance her dog walks provided an explanation for the lack of energy she was feeling and possibly for aches and pains in her legs brought on by old age or sitting still for sustained periods of time.

Whilst Mary's discussions around walking seemed mostly positive, I began to wonder if the elements of walking in the project had the potential to make her appear increasingly confused and disconnected to her current environment. Was I encouraging Mary to withdraw into the past rather than supporting her to connect to the present and in so doing making her actions appear aimless? To address these questions, I began to consider the ways in which artists who walk as part of their practice purposely set out to disrupt the social meanings of place, particularly cities, as part of a creative and political act. Artists often facilitate these walks by following maps or instructions that are intended to represent the geographical layout of the place inaccurately. Guy Debord's famous Parisian dérives in the 1950s used cut up maps to encourage people to drift around the city, a practice that influenced the Mis-Guides and Mis-Guided Tours produced from the 2000s onwards by arts collective Wrights \& Sites. Wrights \& Sites' Mis-Guides instruct people, for example, to take a guidebook from one city and use it to explore another. As they describe in their introduction to their Mis-guides on their website, the aim of this project was to find an alternative way of exploring familiar and unfamiliar places and for participants to engage in a process of discovery. They write: 
Mis-Guides are like no other guides you have ever used before. Rather than telling you where to go and what to see, the Mis-Guide gives you the ways to see your city or environment that no-one else has found yet. A Mis-Guide is both a forged passport to your 'other' city and a new way of travelling a very familiar one. (Wrights and Sites: accessed 2016)

Artists have also developed walks by drawing on experiences of places that happened in the past. Judith Cardiff's audio walk around the Whitechapel area of London was recorded in the 1990s. It captures a walk she went on in a specific place at a specific time. Walked shortly after it was produced it would probably describe the area with some accuracy, although even then some of the more transient activities and conditions recorded during her walk would have ceased and different ones would have commenced. Undertaken today, the extent the area has changed is highlighted by the mismatch between the audio tour and the place in which it is walked. The sounds, descriptions and navigational instructions from the past misguide the walker and create a disjuncture between the activity they are taking part in and the place in which they are undertaking it. An analogy could be drawn between the effect of the outdated audio walk and the effect Gibson describes the occupational and recreational remnants of people with dementia as having when they 'intrude' into their current lives. The difference between these artworks and the walks many people living with dementia take, however, is that for the artists and those who go on their walks it is a choice to temporarily engage in a creative act. For many people living with dementia the realities of living in a place that does not support the activity they are trying to perform is not a choice but something they deal with every day.

As with the walks I have described that were created by other artists, when I walked on the Common I followed instructions based on information Mary gave me that was incomplete and based on recollections of walks that took place in the past. The aim of my first session with Mary was to try and learn about the route she took around the Common so that I could follow it during the weekly walks I planned to take there. I brought with me to the session several images of the Common that I had downloaded from the internet. The only two images Mary told me she recognised were both taken in an area of the Common called the Rookery. One of them was the photograph of an archway and the other was of some 
benches. She also commented when shown another photograph that there were more trees in the Common in which she walked than there was in that image. The difference was so stark to her that she declared this was not a picture of the Common at all.

In response to the information Mary had given me, during my first walk on the Common I located the archway and the benches and went in search of areas with lots of trees. Over the weeks I worked with Mary, through a process of visiting the Common each week before returning to the care home to discuss with her the photographs, films and objects I collected there, I very slowly learnt about other landmarks she used to pass on her walks. In response to a film I made during week two of the project Mary recognised a gate in it and told me that she entered the Common through it after walking up the hill to get to there from where she lived. Her point of entry and the images she had recognised in previous sessions gave some indication of the area of the Common in which she used to walk. When I asked her about the route she walked in the Common, however, she gave me the following vague description, 'I walked up, down and around the Common'. I had no idea how to interpret this and if there was a route she regularly walked on the Common it eluded me.

As a result of the limited information I had about where I should walk, I found myself walking on the Common with no clear direction to my journey. As I carried sticks and balls I had collected because I thought they were the sort of thing someone would throw for a dog, I found myself going on dog walks without a dog. I began to see an analogy between the situation I found myself in and that of care home residents who appeared to wander aimlessly. The term 'wandering' when applied to people who do not have a diagnosis of dementia, however, does not have the negative connotation it does when used to describe walking by people who are living with dementia. In Wanderlust: A History of Walking (2001) Rebecca Solnit applies the terms walking and wandering almost interchangeably as she builds a history of walking in various contexts. She uses wandering to describe walking at a slow pace, that is meandering, that does not have a fixed destination and when it is for leisure, pleasure or exploration. Wandering is walking that is not practical destinationorientated day-to-day walking. She largely uses it as a positive term and, whilst she does on occasion use the word aimless in conjunction with it, this again is not usually done in a negative sense, but often to emphasise a break from the fast pace of contemporary urban 
life. What is more, for Solnit, when wandering is done in the context of art it takes on a more purposeful quality. In a chapter in Wanderlust titled 'The Solitary Stroller and the City' Solnit discusses the walking undertaken by three New York photographers shortly before and after World War II, describing how they wandered to find their subjects. For Berenice Abott, photographing before the War, and Helen Levitt, after it, their subjects were the children playing in the streets, while Weegee's subjects were the fresh corpses on sidewalks and prostitutes in paddy wagons. Solnit describes their activities as follows:

One imagines them wandering purposefully like hunter-gatherers with a camera a sort of basket laden with the day's spectacles, the photographers leaving us not their walks, as poets do, but the fruits of those walks. (Solnit 2001: 189-90)

What I find interesting in this quotation is Solnit's use of the word 'purposefully' to describe their wandering. Particularly as in the following quotation, only a page earlier in the book, she describes her own 'wandering' in New York slightly differently.

Wandering without a clear purpose or sense of direction, I have often disrupted the fast flow of passersby intent on some clear errand or commute, as though I were a butterfly strayed into the beehive, a snag in the stream. (Solnit 2001: 188)

In this second quotation Solnit's wandering has no material product and no predetermined goal. It is contrasted with the destination-orientated walking of the other walkers she encounters, which is performed at a much faster pace than her leisurely one. She is taking her time on her walk, which in itself is the aim of her action -

her walking is not undertaken as a means to arrive somewhere. In the first quotation, however, it is implied by the use of the word 'wandering' that the walk is at a similarly slow pace to that of Solnit's, the journey is also the destination, as with Solnit's, but the camera justifies the wandering by giving the wanderer a reason for their actions, a reason to walk and to do so slowly. To spend time looking around in order to create art whilst walking, Solnit is implying, is purposeful. Her own wandering, she writes 'has no clear purpose' this is not to say it is aimless, just that the aim is not pre-set and is yet to emerge. 
When artists walk as part of their work and when people living with dementia walk as part of their everyday lives they do so for very different reasons and their walking is understood in very different ways. The term 'wandering' has negative connotations when applied to people living with dementia but, I propose, it does not have to have and artists could play an important role in redefining it. The positive use of the term 'wandering' when applied to artists and that they often perform actions in their arts practices that in other contexts may be considered aimless or pointless suggests that their practices question the parameters of what actions are and are not meaningful and of use. It was through a process of creative 'wandering' with Mary that I learnt about her walks and that I supported the continuation of her (virtual) walks even though she was no longer physically able to undertake them. Significantly, as an artist I had a willingness and interest in engaging with something that I realised I did not need to fully understand. In A Field Guide to Getting Lost (2006), another book that she authored, Rebecca Solnit writes:

Lost really has two disparate meanings. Losing things is about the familiar falling away, getting lost is about the unfamiliar appearing. (Solnit 2006: 22)

Conceiving loss as a process of discovering the unfamiliar highlights the productive possibilities of not knowing and analogies can be drawn to physical and virtual wandering, which is intrinsic to the exploratory approaches many artists take to developing work. With this productive concept of getting lost and wandering in mind, I argue that the 'wandering' of the minds of those with and without dementia can be understood as a creative process. It was through a process of setting off on a journey of discovery into the unknown that I found as an artist I could usefully engage with and extend Mary's and my own real and imaginary journeys. Further, it was not in an exact recreation of Mary's walks, but in the relationship between her recollections and my walks that we developed a meaningful and creative dialogue. I was always aware, however, of a need to balance my creative interest with the everyday realities of participants' lived experience and that others they encountered would often not approach their physical and virtual wandering as an artist did.

\section{Leaving the Care Home: Performing Richard Long's Walk}


Anthropologist Tim Ingold argues in his book Being Alive: Essays on Movement, Knowledge and Description (2012) that when people walk they experience the world from a mobile, embodied viewpoint and this informs their knowledge of the places they visit. Advocating walking as a form of research because it reflects the dialogue between locomotion and cognition that he proposes informs most people's experience of a place, Ingold writes:

It is in these dextrous movements along paths of life and travel, I contend, and not in the processing of data collected from multiple sites of observation, the inhabitants' knowledge is forged. Thus locomotion and cognition are inseparable, and an account of the mind must be as much concerned with the work of the feet as with that of the head and hands. (Ingold 2011: 17)

Reflecting on Ingold's ideas about how a knowledge of the world is formed through walking in it, I realised that leaves I had collected from the Common and taken to show Mary in the care home in an attempt to evoke one of my walks were like the data he describes being collected at multiple sites and that they did not reflect the embodied knowledge I had gained as I moved around the Common.

Mary had told me there were lots of trees on the Common. During my second walk on the Common, therefore, I walked from tree to tree collecting as many different leaves as I could find. During that visit to the Common it was a breezy but sunny day with blue skies. The leaves swayed gently in the light wind. They looked almost translucent and their colours appeared vibrant in the strong sun. I plucked a leaf from each type of tree and placed them in a canvas bag. The following day Mary and I picked them out of the bag one by one and laid them out on a dining table. In the still air of the care home the leaves did not move unless we moved them. I noticed that lit by the dining room light their colours looked disappointingly dull against the dark brown wood of the table. I described to Mary how I had collected the leaves from Streatham Common. As she made regular eye contact and postured her body to face me, her body language suggested she was listening, but there was no indication that she made a connection between the leaves and the trees she used to pass on her dog walks. Mary picked the leaves up and looked at them. She appeared to enjoy handling them, talking about their shape and colour and choosing which ones she 
preferred. Similar leaves, however, could have been collected from any number of places. The leaves, isolated from their surroundings and closely examined in the care home environment, did not retain a connection to the Common. The leaves were collected at points along my walk and when presented in the care home held no trace of the embodied journey that connected them. Without the context of the Common, they were no more use in my attempt to communicate my walk than a series of map pins that had fallen out of a map would have been.

Many artists who walk as part of their practice make artworks inspired by their walks to exhibit in galleries. This enables them to communicate something about the walks taken outdoors in an indoor environment. These artworks usually take the form of films, text pieces or photographs. Artist Richard Long's work A Line the Length of a Straight Walk from the Bottom to the Top of Silbury Hill (1970), however, used mud to literally materialise the walk in a gallery. As a visual artist I work with material things. Thinking about how Long had brought the mud from his walk into the gallery helped me to consider how the materials I brought into the care home from my own walks on the Common evoked a sense of these walks and to question their material, performative and spatial possibilities and limitations.

Long made A Line the Length of a Straight Walk from the Bottom to the Top of Silbury Hill by walking from the base to the summit of Silbury Hill in Wiltshire in a straight line. He then recreated the walk in a gallery. To transfer the walk into the gallery space Long walked in a line that was the same length as the one he had walked up the hill. When he walked it in the gallery, however, he could not walk the distance in a straight line because the dimensions of the space were too small. Instead he chose to walk in a spiral. Whilst this was not the only way he could have fitted the line in, any configuration he chose would have involved the line bending. It was not possible to fit the straight line he had walked up the hill into the indoor venue of the gallery.

The other difference between the line he walked up the hill and the line he walked in the gallery that is significant here is the way he drew the line with his feet. When he walked up the hill the weight of his body pressing through his shoes imprinted the earth leaving a negative space in the shape of the sole of the shoe. When he recreated the walk in the 
gallery he dipped his walking boots into mud that he had collected from the hill and made footprints with them on the floor. The floor, unlike the ground outside on the hill, did not allow his footprints to penetrate its surface. Instead the mud sat on top of the hard, nonporous floor designed to be cleaned and to leave no trace of the feet that walk over it. These two significant differences between Long's walk up the hill and his recreation of the walk in the gallery highlight how the representation of the experience needed to be adjusted to accommodate the differences in scale and materiality between the outdoor and indoor spaces. Whilst the gallery is undeniably a very different type of space to the care home it is on a comparable scale to many of the rooms the sessions took place in and is an indoor environment that shares some similarities with their physical properties, significantly for this discussion the non-porous floor. The curled up line of Long's muddy footprints introduces materials associated with the outdoors into an indoor environment and provides a strong visual metaphor for the outdoor walk. However, it also highlights for me some of the difficulties with being a visual artist who is trying to quite literally materialise an experience in a care home and is encountering the limitations of the materials I am bringing in and those of the space itself.

Prior to starting my research I had become interested in Ingold's idea of 'pedestrian touch' and had applied it to how I researched the walks I took outdoors and in the care home, but I had not consider how it could effect my approach to attempting to evoke the walks in the sessions I facilitated. Through his discussion of pedestrian touch, Ingold argues that a dialogue between the walker's gait and the materiality and gradient of the ground on which they walk can inform their knowledge of the environment they walk in. He argues that a knowledge of an environment can be gained by feeling the surface or contours of the ground. Positioning walking in relation to other modes of transportation, such as cars or planes that transport people at speed in a seated position and during which journeys they do not touch the ground, he reasons that 'it is surely through our feet, in contact with the ground [...], that we are most fundamentally and continually 'in touch' the substance, texture and gradient of the ground on which they walk. Steps are, Ingold writes, 'continually and fluently responsive to an ongoing perceptual monitoring of the ground ahead' (Ingold 2011: 46). 
As I walked on the Common along gravel, tarmacked and paved paths, across grassy fields and, on days when it had rained, through mud and puddles, I was very aware of how these changes in the ground affected how I placed my feet upon it. As the ground I trod on was never exactly the same, so one step never exactly replicated the next. The rhythm of my walks was produced through a dialogue between the gait of my body and the ground on which I trod. Walks, therefore, do not keep a constant tempo but one that is irregular. Writing about the rhythm of walking, Ingold purports that steps are 'rhythmic rather than metronomic, what they beat out is not a metric of constant intervals but a pattern of lived time and space.' (Ingold 2011: 46).

Even if I had spaced the leaves out, arranging them around the room to represent the spaces in which I walked between the trees, I would still have had to do something more to evoke the journey that happened in the gaps between them. Long had his spiral of footprints that represented the length of his walk, but I could not walk muddy footprints all over the floor of the dining room, which straight after our session had finished each week was set up for lunch. Further, I began to question how much of the rhythm of Long's walk up the hill was communicated through his footprints in the gallery. Surely they had a different rhythm to those of Long's earlier walk, one that responded to the substance and gradient of the gallery floor. Thinking about this raises further questions about whether the rhythm of my walks could be communicated by any object I brought into the care home.

In the workshops I facilitated with dancer Christina Argyropoulou, she introduced the movement of walking into the dining room in which the sessions took place. She facilitated activities that encouraged participants to walk. They did so, however, from a seated position. Each week the participants sat in chairs arranged in a circle and most sessions began with her leading movement exercises connected to modes of travel; walking, running, swimming, driving and cycling. During the walking actions their feet did not go anywhere beyond the reach of their seated body, they were walking on the spot and the spot that they were walking on was cushioned by a short-pile carpet. No footprints were made and the scenery did not change. Despite all that was missing from or contradictory to the experience of being on a walk, either because of the environment or their body's movements, most participants embraced the action of walking. The walking they undertook 
despite being seated was much more energetic than most of the walks I observed care home residents taking in corridors. Many of the participants who moved vigorously in these activities had been supported to walk to the sessions by care staff and were unable to stand unaided. In the sessions they walked with intent, with arms moving at their sides propelling them forward and head and eyes facing straight ahead. There was a clear recognition in the way they performed the actions that they had experienced and could recall the action of walking. Not the kind of walking that takes place in a domestic space that is usually slower and over a shorter distance, but a long, determined, energetic hike or brisk walk to the shops, for example. The movements by my co-facilitated achieved a connection to the rhythms of walking that the leaves I introduced during my sessions with Mary failed to evoke.

During the movements led by Argyropoulou the participants were not only carried along by the action of walking, but, as I observed the rhythms of their movements aligning as a group, it appeared they were also carried along by each other. As they mirrored each other's movements and the pace built and dipped there was a sense of a shared rhythm. In his book Refrains for Moving Bodies: Experience and Experimentation in Affective Spaces (2013) Derek P. McCormack argues that rhythms can be transmitted between bodies because of the affective qualities that they produce. He defines affective qualities as; ' $[\mathrm{t}]$ hose heterogeneous matters of the sensible world we often try to capture through terms such as emotion, mood, and feeling.'(McCormack 2013: 2)

The mood I sensed from most participants during the walking activities was one of determination and sometimes elation. This differed significantly to the lethargic, disengaged mood I sensed when I entered the room before the sessions began and the majority of care home residents were sitting sleeping or not interacting with anyone or anything. McCormack argues that to understand how places are produced for and by moving bodies is to understand the dialogue between the physical space and the people within it. People can have a significant impact on how a place is experienced because an action performed by one person is experienced not just by them but by others who share the same space. McCormack proposes that bodies need to be thought of beyond the physical form that they occupy and this involves, he writes: 
[T]hinking of bodies as lively compositions crossing thresholds of intensive and extensive consistency whose limits are defined less by physical boundaries than by capacities to affect and be affected by other bodies' (McCormack 2013: 2)

Writing about a week-long residency he undertook in a corridor of Chisenhale Dance Studios, McCormack describes how the physical space and the purpose it is designed to fulfil can determine the movements of the people who are in it. Corridors are usually designed as passages that physically connect one place to another and are, therefore, primarily places people pass through rather than places to pause and spend time. The corridor McCormack's residency took place in was no exception to this design and use. Describing the movements of the people he encountered in the corridor at the start of the residency he writes:

$[T]$ he rhythm of these movements is relatively predictable. Bodies go with the flow. Move along, nothing of interest here' (McCormack 2013: 32)

He noticed, however, as the residency progressed that by spending extended periods of time in a space that is not designed for pausing in he was not only affected by its rhythms but began to affect other people's rhythms. He writes of spending time in the corridor:

To pass time in this space is not, however, to accede inevitably to its rhythms: it is also to modify them, and to generate new rhythms with the potential to be felt across and between bodies. (McCormack 2013: 32)

It is a modification of the rhythms of the space, similar to those McCormack describes, that I propose the dancer's walking movements achieved in the sessions in the care home. Instead of slowing down the pace of the environment as McCormack did, conversely, they speeded up and enlivened an otherwise stagnant place. This was something that I found from my experience of walking in the corridor with Mary sometimes could not be achieved by actually walking somewhere with a care home resident. When I walked down the corridor with Mary, rather than me speeding her up, I could feel her slowing me down. What is more, I could feel the effort Mary was putting into walking down the corridor. As I fell into 
step with Mary she leaned into me and trod carefully, each jolting step appearing to take mental and physical effort, and she regularly needed to take a rest about half way down the corridor. It was this effort that made me, not just realise, but feel that this was now a long walk for Mary, who had once regularly taken much longer walks with her dog on the Common. Mary's physical world had shrunk but she appeared to experience the corridor as a significant distance to walk. When care home residents who I had observed having a similarly slow pace to Mary participated in Argyropoulou's walking activities, however, the chair supported the weight of their bodies and freed them up to walk more vigorously.

The shape of my arts sessions with Mary was focussed in on us as art partners (Mayo 2012). This is partly because I am a visual artist and partly because this is the shape most one-toone projects take because they are just that, one-to-one. When I used objects in my project with Argyropoulpou I consciously worked towards opening out the shape of my practice to include the whole group and found that it was possible to use objects, drawing and making whilst still engaging with all the participants. The dancer in her walking activities, however, went beyond opening the activity out to the whole group. She carried participants along and their awareness was not focussed on their surroundings, but on the embodied experience they were feeling. In my participatory arts practice I felt like I was stuck with a metaphorically curled up line, but in the movement activities, whilst everyone remained on the spot, the line straightened out and extended beyond the room as the participants went for a virtual walk outside.

It was only when the rhythm of the dancer's practice was combined with the gestural drawing and materiality of mine that I found the line of my practice could be uncurled. This did not happen in our project until week nine when we drew with long garden canes with sponges on the end into flour and glitter covered sheets of paper arranged in the middle of the circle in which we were sitting (fig. 1). The length of the garden canes increased the breadth of movement in the drawing activity and the movements we led for residents to copy created a rhythm, as did the 'blizzard' of flour and glitter that bounced off the paper as we hit it with the garden canes. 
I was finally able to take a line for a walk that was both material and embodied. It did not replicate the rhythm, materiality, sensory or aesthetic qualities of a walk outdoors. Instead it trod a careful path embodying the care home residents' current experiences and those they carried with them in their memory and imagination. Further, it walked a line between my own arts practice and that of the dancer. It is through a process of wandering in these inbetween spaces that are often unknown and require an exploratory and responsive approach that artists and people living with dementia can walk together. The challenge, perhaps, lies in how others are brought along on these journeys, particularly professional carers whose roles exist within communities of practice (Wenger 1998) in which they follow practices and procedures that are often task-based and time limited and where it is not immediately obvious if and how they are conducive with the approaches artists take.

\section{References}

All-Party Parliamentary Group on Arts, Health and Wellbeing Inquiry Report. 2017. Creative Health: The Arts for Health and Wellbeing.

Basting, Anne Davis. "'God is a Talking Horse": Dementia and the Performance of Self." TDR (1988---) 45.3 (2001): 78-94.

Department of Health. 2015. Health Building Notes 08-02: Dementia-friendly Health and Social Care Environments.

De Medeiros, K., \& Basting, A. 2014. 'Shall I Compare Thee to a Dose of Donepezil?': Cultural Arts Interventions in Dementia Care Research. The Gerontologist, 54(3), 344-353

Gibson, F. 2006. "Life Factors Influencing Present Behaviour." Ed. Marshall, Mary and Kate Allan. Dementia Walking Not Wandering: Fresh Approaches to Understanding Practice. London: Hawker.

Heddon, D. and Turner, C. 2012. Walking women: shifting the tales and scales of mobility. Contemporary Theatre Review, 22(2), pp. 224-236 
Heddon, D. and Porter, S. 2014. Walking in Someone Else's Shoes www.falmouth.ac.uk/whereto/heddon-porter

Ingold, T. 2011. Being Alive: Essays on Movement, Knowledge and Description. Oxon, UK: Routledge.

Marshall, M. 2006. “Design for Walking: Creating Rich Environments." Ed. Marshall, Mary and Kate Allan. Dementia Walking Not Wandering: Fresh Approaches to Understanding Practice. London: Hawker.

Mayo, S, O'Dair, C, and McAvinchey, C. 2012. Detail and Daring : Research into the Art and the Craft of Intergenerational Work. London.

McCormack, Derek P. 2013. Refrains for Moving Bodies: Experience and Experiment in Affective Spaces. USA: Duke University Press.

Myers, Misha. 2017. "Way From Home: Sharing a Walk Elsewhere." Livingmaps Review Solnit, Rebecca. 2006. A Field Guide to Getting Lost. Edinburgh: Canongate, 2006.

Solnit, Rebecca. 2001. Wanderlust: A History of Walking. London: Verso.

Wenger, Etienne. 1998. Communities of Practice: Learning, Meaning and Identity. Cambridge University Press.

Wrights \& Sites website, http://www.mis-guide.com/mg.html. Accessed 5th Mar. 2016.

Zeilig, Hannah, John Killick, and Chris Fox. 2014. "The Participative Arts for People Living with a Dementia: A Critical Review." International Journal of Ageing and Later Life 9.1. p734. 